\title{
Preparation of Inclusion Complex of Piroxicam with Cyclodextrin by Using Supercritical Carbon Dioxide
}

\author{
Martial Sauceau*, Elisabeth Rodier, Jacques Fages \\ RAPSODEE centre, UMR EMAC-CNRS 2392, École des Mines d'Albi, 81013 Albi, \\ France \\ * Corresponding author. - Tel : 33 (0)5 634933 18 - Fax : 33 (0)5 63493243 \\ E-mail address: martial.sauceau@enstimac.fr
}

\begin{abstract}
Forming complexes with cyclodextrins can enhance the dissolution rate, the stability, the solubility and the bioavailability of a drug. In this work, piroxicam/ $\beta$-cyclodextrin complexes were prepared at solid state by means of supercritical carbon dioxide. The influence of temperature, residence time, water content and a ternary agent, L-lysine, were studied. The complex was characterized by Differential Scanning Calorimetry, Scanning Electronic Microscope and dissolution profile in water. Finally, a complete inclusion was achieved for a piroxicam/ $\beta$-cyclodextrin/L-lysine mixture by keeping a physical mixture of the three compounds $\left(1: 2: 1.5\right.$ molar ratio) for 2 hours in contact with $\mathrm{CO}_{2}$ at $150^{\circ} \mathrm{C}$ and $15 \mathrm{MPa}$.
\end{abstract}

Keywords: piroxicam; cyclodextrin; complex; ternary agent; supercritical carbon dioxide

\section{Introduction}

Novel pharmaceutical molecules often exhibit a limited solubility in water, the major component of biological fluids. Thus, a difficult challenge is to make these molecules available for their biological targets. Various methods have been used to increase their dissolution rate, including micronisation, modification of the physico-chemical properties of the drug and complexation with cyclodextrins (CD). 
Micronisation may lead to the enhancement of powders dissolution rate by increasing their specific surface area. The classical processes, crushing/milling and liquid crystallisation are still the most used [1]. However, supercritical fluid (SCF) technology presents a new and interesting route, which avoids most of the drawbacks of the traditional ones [1,2]. A SCF is a fluid used at temperatures and pressures above its critical values. The interest in using this technology is due to the special properties that are inherent to this class of fluid, including the ability to vary solvent density and properties by changing either the pressure or the temperature. Moreover, additional advantages lie in the use of carbon dioxide $\left(\mathrm{CO}_{2}\right)$ which properties of non-toxicity and mild critical conditions make it an ideal substitute to organic solvents. $\mathrm{CO}_{2}$ is gaseous at ambient conditions, which simplifies the problem of solvent residues. Classical particle generation processes using SCF, mainly RESS (Rapid Expansion of a Supercritical Solution), SAS (Supercritical Anti-Solvent) and PGSS (Particles from GasSaturated Solution), can lead to the enhancement of powder dissolution rate by increasing the specific surface area. However, other properties like wettability of the powder could be an important parameter to consider and, in addition, the increase due to higher surface area could be insufficient [3].

Another way to increase powder dissolution consists in complexation with CD. CD are tronconic shaped cyclic oligosaccharides consisting of D-glucopyranose units linked by glycosidic bonds (Figure 1). Commercially available CD consist of six, seven or eight D-glucose units and are referred as $\alpha-, \beta$ - and $\gamma-\mathrm{CD}$ respectively. As the outside surface of these molecules is hydrophilic and the inside surface hydrophobic, they are able to include, fully or partially, in their cavity large organic molecules by non-covalent interaction forces (hydrogen bonds, Van der Waals forces). Physical and chemical properties of the included molecules may thus be favourably modified, and in particular the physical stability and the aqueous solubility can be improved $[4,5]$.

However, due to various reasons including cost, toxicology and dosage, the amount of $\mathrm{CD}$ that can be used in most formulations should be restricted [6]. Therefore, different methods have been undertaken to improve their performance. Among the possible different approaches, recent works showed that the addition of suitable auxiliary substances can significantly increase the $\mathrm{CD}$ solubilising and complexing abilities by multicomponent 
complex formation [6]. For instance, it has been shown that the addition of hydroxy- or amino-acids can lead to the improvement of CD performance, which can be seen as a result of the combined effects of salt formation and inclusion complexation $[7,8,9,10]$.

Several techniques have been used to prepare an inclusion complex, including kneading, grinding, freeze drying or crystallization. However, the disadvantages of using some of these methods lie in the poor aqueous solubility of many non polar drugs. In addition, they are time and energy consuming, necessitate multistage processing and often result in residual solvent in the product.

One of the techniques developed to overcome these drawbacks uses SCF [11]. In 1990, Kamihira et al. used CD for the entrapment of volatile aromatic compounds after extraction with pressurized $\mathrm{CO}_{2}$ at $10 \mathrm{MPa}$ and $20^{\circ} \mathrm{C}$ [12]. In 1996, Giordano et al. studied the interaction of supercritical (SC) $\mathrm{CO}_{2}$ with a drug/cyclodextrin inclusion compound and the possibility of extracting the drug from the inclusion compound by supercritical extraction [13]. In 1999, Van Hees et al. prepared a piroxicam/ $\beta-C D$ inclusion compound by pressurising in a static mode a physical mixture of the two compounds with $\mathrm{SC} \mathrm{CO}_{2}$ up to $45 \mathrm{MPa}$ and $150^{\circ} \mathrm{C}$ [14]. More recently, drug/CD complexes were successfully prepared in SC media by dynamic or static methods for several molecules (Table 1 [12-57]). Complexes of miconazole and piroxicam have also been prepared with the addition of ternary compounds [15-18]. In 2003, a three-step process has allowed the bioavailability enhancement of eflucimibe [21] and the scaling up of the technology has been successfully studied [22].

Piroxicam (PI) is a non-steroidal anti-inflammatory drug (NSAID) that also possesses analgesic and antipyretic properties (Figure 2). Its major indications are inflammatory and degenerative rheumatism, acute post-traumatic musculoskeletal disorders, and the symptomatic treatment of acute arthritis [58]. Literature already describes an inclusion complex of PI with $\beta-C D$ in a molar ratio of 1:2.5 which, in comparison with neat PI, shows improved wettability and water solubility, higher plasma concentration $\left(\mathrm{C}_{\max }\right)$, takes less time to reach the peak concentration $\left(\mathrm{T}_{\max }\right)$ and reduces gastrointestinal side effects $[59,60]$. 
The aim of this work is to prepare inclusion complexes between PI and $\beta$-CD by using $\mathrm{SC} \mathrm{CO}_{2}$ and to study the influence on the inclusion yield of operating parameters as temperature, duration or composition. As an ammonium hydroxide solution is added for the preparation of the spray-dried inclusion complex [61], the influence of a ternary alkaline compound on inclusion is also investigated. However, supercritical ammoniac is highly corrosive and would deteriorate the high pressure stainless steel vessel. Therefore, a weaker alkaline agent, the L-lysine (LL), is used [15].

\section{Materials and methods}

\subsection{Materials}

$\mathrm{CO}_{2}$ was purchased from Air Liquide S. A. (purity 99.995\%), PI and LL from Sigma Aldrich (purity 99.99 and 98\% respectively) and $\beta$-CD from Acros Organics (purity 99\%). Distilled water was used.

\subsection{Complex preparation}

The process was carried out by means of a polyvalent pilot plant (Separex, France), equipped with two 2-liter vessels by following an operating mode already described [56]. Approximately $10 \mathrm{~g}$ of a physical mixture of each different compound was prepared. It has to be noted that the water is always added in last. Then, the physical mixture was put in a cylindrical 1.5-liter stainless steel cartridge closed at its extremities with stainless steel sintered disks. The vessel, inside which the cartridge has been placed, is heated and pressurized at the required temperature and pressure and left in a static mode. At the end of the process, the vessel was depressurized to atmospheric pressure and the content of the vessel was ground and homogenized in a mortar.

\subsection{Thermal analysis}

Thermal analysis was performed on about $5 \mathrm{mg}$ sample by using a Differential Scanning Calorimetry (DSC, Model 7, Perkin Elmer, France) between 50 and $250^{\circ} \mathrm{C}$ at a heating rate of $10^{\circ} \mathrm{C} . \mathrm{mn}^{-1}$ under a $\mathrm{N}_{2}$ gas stream. 
Redenti at al. [62] successfully used thermal analysis for differentiating a PI/ $\beta$-CD true inclusion complex and a physical mixture of the two amorphous components. As PI exhibits a high tendency to crystallize, the measurement of the melting peak area allows evaluation of the free PI content, irrespective of its amorphous or crystalline state.

In Figure 3, typical curves of both physical mixture and SCF processed sample are depicted. The DSC curve of the physical mixture shows two peaks: a broad endotherm between 50 and $100^{\circ} \mathrm{C}$ corresponding to the water loss of the $\beta-\mathrm{CD}$, followed by an endothermal peak at about $200^{\circ} \mathrm{C}$ characteristic of the crystalline piroxicam melting. When working with SCF, the disappearance of the endothermic peak is considered as an evidence of the inclusion phenomenon. Thus, an inclusion yield, $T_{C X}^{P I}$, was calculated with the following expression:

$$
T_{c x}^{P I}=\left(1-\frac{\Delta H_{e x}^{P I}}{\Delta H_{t h}^{P I}}\right) * 100
$$

$\Delta H_{e x}^{P I}$ is the enthalpy corresponding to the melting peak of PI measured for the sample and $\Delta H_{t h}^{P I}$ is the theoretical enthalpy if no inclusion occurs. $\Delta H_{t h}^{P I}$ is calculated from enthalpy measured for pure PI, proportionally to the weight concentration of PI in the sample.

The relevance of this procedure has been confirmed by Van Hees et al., who have obtained the same results with this method and the differential solubility method [63].

\subsection{Visualisation}

The samples were observed using an Environmental Scanning Electronic Microscope XL30 ESEM FEG (Philips, Netherlands).

\subsection{Drug content and dissolution kinetics studies}

In vitro dissolution studies were performed in the same conditions for all samples. A quantity of powder equivalent to $50 \mathrm{mg}$ of PI was introduced in $50 \mathrm{ml}$ of water at $37^{\circ} \mathrm{C}$ and stirred with a magnetic stick. To determine the corresponding sample weight to be introduced, and thus to check that no PI was extracted or deteriorated during SCF process, PI content was measured by HPLC for all samples. During dissolution, samples were collected at different intervals, filtered $(0.45 \mu \mathrm{m})$ and the PI content in the filtrates was analysed by HPLC. 


\section{Results}

The operating conditions of the experiments are presented in Table 2. The corresponding inclusion yield $T_{C X}^{P I}$, calculated according to Eq. (1), is also reported in this table. A previous study showed that pressure had little influence in the range 15-45 $\mathrm{MPa}$ [14]. In the beginning of this study, the pressure of $\mathrm{CO}_{2}$ was fixed at $15 \mathrm{MPa}$. As in some cases a complete inclusion could be obtained, the influence of pressure was no more deeply investigated.

To check the reproducibility of the experiments, four of them have been carried out twice (experiments \# 6-\# 21, \# 7-\# 12-\# 18, \# 10-\# 15 and \# 22-\# 23). As can be seen in Table 2 , results are similar with a standard relative deviation less than $2 \%$.

The first experiments have been carried out with a molar ratio of PI: $\beta$-CD:LL equal to $1: 2.5: 1$ and a water content of $27.5 \%$ to observe the influence of temperature for a two hours duration (\# 1 to \# 5). These data suggest that there is a shift in the equilibrium toward the complexed form with an increase in the temperature. For the following experiments, the temperature was fixed at $150^{\circ} \mathrm{C}$.

The influence of water content has been examined, with or without the addition of LL in the mixture (\# 6 to \# 8 and \# 9 to \# 11 respectively). A water content of $9 \%$ corresponds to the natural hydration of $\beta-\mathrm{CD}$ and a content of $27.5 \%$ to a maximum before obtaining a paste. On the basis on these results, it is clear that the additional water is essential for complexation.

The experiment \# 6 shows that a PI: $\beta$-CD molar ratio of 1:2 provides the same inclusion rate than a 1:2.5 ratio. It also confirms previous results of Van Hees et al. [15]. These authors have studied the influence of the PI: $\beta$-CD molar ratio between 1:0.5 and 1:2.5 and have observed the highest inclusion yield with a 1:2 molar ratio.

The experiments \# 12 to \# 17 have investigated the exposure time to $\mathrm{SC} \mathrm{CO}_{2}$ at $15 \mathrm{MPa}$ and $150^{\circ} \mathrm{C}$ at an intermediate water content, with and without LL. In the presence of LL, the duration had a positive influence on inclusion yield by increasing the contact time. Without LL, inclusion yield was also improved for lower contact times but remained more or less constant for higher duration. In these operating conditions, we can finally conclude that a too 
high duration is required to obtain a sufficiently high inclusion yield. It also appears from the former experiments that LL does have a dramatic positive effect on the inclusion efficiency. Thus, the LL effect has been deeply investigated in experiments \# 18 to \# 22 .

All the results for two hours duration at $15 \mathrm{MPa}$ and $150^{\circ} \mathrm{C}$ are summarized on Figure 4. This figure shows the inclusion yield as a function of LL molar ratio for the three water content levels tested. Finally, a combination of a high water content $(27.5 \%)$ and a molar excess of LL in comparison with PI allows to obtain a complete inclusion (\# 22).

The $\gamma$-CD has also been tested in the operating conditions that have provided an almost complete inclusion with $\beta$-CD (the yield was $94 \%$ ). A lower inclusion was obtained with this $\gamma-\mathrm{CD}$, with a yield equal to $76 \%$.

The Figure 5 presents the SEM pictures of raw materials. We can observed large wellformed crystals of PI and large plate particles of CD. A visual observation of the processed powders has shown two main aspects in the materials obtained: either yellow clusters or slightly browned powders, the higher the inclusion yield the higher proportion of clusters. Both were separated, submitted to thermal analysis and observed with SEM (Figure 6). The inclusion yield measured for browned powder and yellow clusters are 33 and $99 \%$ respectively. Thus, the powder corresponds to partially complexed PI whereas clusters are completely complexed PI. On Figure 6, we can see that a homogeneous cubic structure appears in yellow clusters when complex formation is achieved. In browned powder, this cubic structure coexists with large particles on which some fibers are deposited. Large particles correspond to pure CD and PI crystals are no more distinguishable. Fibers are probably PI which crystallized during the pressure drop at the end of the process. This evolution of structure was already observed in previous works during complex formation [21, 56]. Finally, the visual observation of the material provides a means to control the advancement of the process.

Figure 7 shows the results of dissolution tests for unprocessed PI and three physical mixtures with $\beta$-CD and LL, two binary and one ternary. In the case of physical mixtures, PI dissolution is practically not modified by the presence of $\beta-C D$ but is largely enhanced by LL, 
irrespective of the presence of $\beta-C D$. This observation seems to be in contradiction with the high effect of the LL on the inclusion yield previously noted.

Dissolution profiles for four SCF processed samples are presented on Figure 8 (samples \# 19, \# 20, \# 22 and \# 24). Sample \# 19 exhibits a dissolution profile similar to that of the physical mixture, but is completely dissolved after $60 \mathrm{~min}$. This can be explained by the high LL content of this sample. Sample \# 20 presents an instantaneous dissolution that remains constant at a lower level than that of \# 19 (about $500 \mu \mathrm{g} \cdot \mathrm{ml}^{-1}$ ), in spite of its higher inclusion yield ( $73 \%$ instead of $52 \%$ ). The instantaneous dissolution is probably due to the included fraction of PI, but the low LL content (0.5) does not allow a higher dissolution. The sample \# 24 , with an inclusion yield similar to \# 20, exhibits the same dissolution profile at however a higher level. This can be explained both by the higher aqueous solubility of $\gamma$-CD in comparison to $\beta$-CD (233 and $18.5 \mathrm{~g} \cdot \mathrm{mol}^{-1}$ at $25^{\circ} \mathrm{C}$ respectively) and by the higher LL content. Finally, the dissolution of sample \# 22, entirely included, is complete and instantaneous.

\section{Discussion}

It is clear that the additional water is essential for complexation to occur and that the higher the water content the higher the inclusion level. This added water acts in two ways: solubilization of the surface of CD promoting surface cracking (Figure 6) and increasing the surface of contact and destabilization of water present in the CD cavities. This internal water may become unstable with a higher energy state, supporting its replacement by PI molecules $[56]$.

It has also been observed that the way physical mixture is prepared could also influence the complex formation of ketoprofen, an active substance [56]. Indeed, the addition of water in the physical mixture before active substance seems to make more difficult the association of $C D$ with active substance. It has been explained by the stabilization of the water structured into the $\mathrm{CD}$ cavities and the inhomogeneous distribution onto CD surface of hydrophobic active substance. On the contrary, the addition of water after the active substance has exhibited an important positive effect on complexation of ketoprofen. The second procedure 
has been used in this work.

In the experimental conditions used, a minimum temperature of $140^{\circ} \mathrm{C}$ is necessary to obtain the higher inclusion. This is in agreement with the PI results of Van Hees et al. [14], who have observed at $15 \mathrm{MPa}$ for $3 \mathrm{~h}$ an increase of the inclusion yield from $4 \%$ at $100^{\circ} \mathrm{C}$ to $85 \%$ at $150^{\circ} \mathrm{C}$. The inclusion yield seems to be controlled rather by transfer and association phenomena than PI solubility in supercritical $\mathrm{CO}_{2}$, as observed by Rodier et al. [21]. Indeed, in $\mathrm{SC} \mathrm{CO}_{2}, \mathrm{CD}$ were found to be insoluble [30] and PI solubility decreases with temperature at $15 \mathrm{MPa}[14,64]$. On the contrary, the $\mathrm{CO}_{2}$ viscosity decreases with temperature and thus, the $\mathrm{CO}_{2}$ diffusivity and the diffusion coefficient of a solute in $\mathrm{SC} \mathrm{CO}_{2}$ increases [65]. Moreover, at higher temperatures, water in the cavities becomes less stable, and thus more likely leaves the cavities to be replaced by PI [56].

The addition of LL, in presence of added water, shows a dramatic positive effect on the inclusion efficiency. Others kinds of studies like NMR spectroscopy or molecular dynamics are necessary to conclude if L-lysine reinforces the formation of the inclusion complex. However, during dissolution tests, no synergistic effect on PI solubility enhancement is observed in ternary system. This observation seems to indicate on contrary no specific involvement of LL in the molecular assembly of a ternary complex $[9,10]$. Another way of explanation is thus based on the wetting ability of the LL, which would allow a better water distribution on the powder and an increase of the association.

Finally, a combination of a high water content $(27.5 \%)$ and a molar excess of LL in comparison with PI allows to obtain a complete inclusion. The dissolution of this entirely included sample is complete and instantaneous. This confirms the relevance of DSC to control the effectiveness of the SC treatment, as it is easier to implement than dissolution test.

\section{Conclusion}

Complexation with $\mathrm{CD}$ is an interesting method to improve aqueous dissolution of poorly water-soluble drugs. In this work, inclusion complexes of PI with $\beta$-CD and $\gamma$-CD have been prepared by using $\mathrm{SC} \mathrm{CO}_{2}$. The process consists in a static step during which the powder is submitted to pressurized $\mathrm{SC} \mathrm{CO}_{2}$. A combination of a high water content, the use of 
L-lysine as ternary agent and a temperature higher than $140^{\circ} \mathrm{C}$ allows to reach high inclusion yield. Finally, a complete inclusion was achieved for 2 hours at $15 \mathrm{MPa}$ and $150^{\circ} \mathrm{C}$ with a molar excess of LL and $27.5 \%$ of water. The SEM pictures of processed powders shows that a homogeneous cubic structure appears when complex formation is achieved.

The aqueous dissolution rate of the complex formed by $\mathrm{SC} \mathrm{CO}_{2}$ was found to be significantly higher than that of the physical mixture of the components. This study demonstrates that a supercritical process can be efficient to form an inclusion complex in solid state. This method is attractive since $\mathrm{CO}_{2}$ leads to powders free of organic solvent. It can also limits drug degradation, although it could imply a too high temperature. 


\begin{tabular}{|c|c|}
\hline Drug & References \\
\hline geraniol, mustard oil & {$[12]$} \\
\hline acetaminophen & {$[13]$} \\
\hline piroxicam & {$[14,15]$} \\
\hline miconazole & {$[15,16,17,18,19,20]$} \\
\hline Eflucimibe & {$[21,22]$} \\
\hline ibuprofen & {$[23,24,25,26,27,28,29]$} \\
\hline naproxen & {$[28,30,31,32]$} \\
\hline flurbiprofen & {$[28]$} \\
\hline citral, thymol, carvacrol & {$[33]$} \\
\hline imazalil & [34] \\
\hline salicylic acid & {$[35]$} \\
\hline azobenzene & {$[36]$} \\
\hline budesonide & {$[37,38,39]$} \\
\hline indomethacin & {$[40]$} \\
\hline polyaniline & [41] \\
\hline cholesterol & {$[42]$} \\
\hline arylphosphines & {$[43]$} \\
\hline itraconazole & {$[44,45,46]$} \\
\hline 2 sodium salts & [47] \\
\hline hydroxyflavone & {$[48]$} \\
\hline benzocaine & {$[50,49]$,} \\
\hline bupivacaine, and mepivacaine & {$[50]$} \\
\hline simvastatin & {$[51]$} \\
\hline several triphenyl phosphine derivatives & {$[52]$} \\
\hline all-trans-lycopene & {$[53]$} \\
\hline 15 carbohydrates & {$[54]$} \\
\hline human serum immunoglobulin $\mathrm{G}$ & {$[55]$} \\
\hline ketoprofen & {$[56]$} \\
\hline econazole & {$[57]$} \\
\hline
\end{tabular}

Table 1. Drug/CD complexes prepared in SC media by dynamic or static 


\begin{tabular}{|c|c|c|c|c|c|c|c|}
\hline \multirow[t]{2}{*}{ Sample } & \multicolumn{3}{|c|}{ Mixture } & \multicolumn{3}{|c|}{ Supercritical process } & \multirow{2}{*}{$\begin{array}{c}T_{C X}^{P I} \\
(\%)\end{array}$} \\
\hline & CD & $\begin{array}{c}\text { Molar ratio } \\
\text { PI:CD:LL }\end{array}$ & $\begin{array}{c}\mathrm{H}_{2} \mathrm{O} \\
\text { (\% mass.) }\end{array}$ & $\begin{array}{c}\mathbf{P} \\
(\mathbf{M P a})\end{array}$ & $\mathbf{T}\left({ }^{\circ} \mathrm{C}\right)$ & t (h) & \\
\hline$\# 1$ & $\beta$ & $1: 2.5: 1$ & 27.5 & 15 & 150 & 2 & 92 \\
\hline$\# 2$ & $\beta$ & $1: 2.5: 1$ & 27.5 & 15 & 140 & 2 & 91 \\
\hline \#3 & $\beta$ & $1: 2.5: 1$ & 27.5 & 15 & 130 & 2 & 63 \\
\hline$\# 4$ & $\beta$ & $1: 2.5: 1$ & 27.5 & 15 & 120 & 2 & 66 \\
\hline \# 5 & $\beta$ & $1: 2.5: 1$ & 27.5 & 15 & 110 & 2 & 57 \\
\hline$\# 6$ & $\beta$ & $1: 2: 1$ & 27.5 & 15 & 150 & 2 & 94 \\
\hline \# 7 & $\beta$ & $1: 2: 1$ & 20 & 15 & 150 & 2 & 48 \\
\hline$\# 8$ & $\beta$ & $1: 2: 1$ & 9 & 15 & 150 & 2 & 0 \\
\hline \# 9 & $\beta$ & $1: 2: 0$ & 27.5 & 15 & 150 & 2 & 20 \\
\hline \# 10 & $\beta$ & $1: 2: 0$ & 20 & 15 & 150 & 2 & 0 \\
\hline \# 11 & $\beta$ & $1: 2: 0$ & 9 & 15 & 150 & 2 & 0 \\
\hline$\# 12$ ( \# 7) & $\beta$ & $1: 2: 1$ & 20 & 15 & 150 & 2 & 47 \\
\hline \# 13 & $\beta$ & $1: 2: 1$ & 20 & 15 & 150 & 5 & 49 \\
\hline \# 14 & $\beta$ & $1: 2: 1$ & 20 & 15 & 150 & 16 & 60 \\
\hline$\# 15$ ( \# 10) & $\beta$ & $1: 2: 0$ & 20 & 15 & 150 & 2 & 0 \\
\hline \# 16 & $\beta$ & $1: 2: 0$ & 20 & 15 & 150 & 5 & 15 \\
\hline \# 17 & $\beta$ & $1: 2: 0$ & 20 & 15 & 150 & 16 & 11 \\
\hline$\# 18$ ( \# 7) & $\beta$ & $1: 2: 1$ & 20 & 15 & 150 & 2 & 50 \\
\hline \# 19 & $\beta$ & $1: 2: 1.5$ & 20 & 15 & 150 & 2 & 52 \\
\hline \# 20 & $\beta$ & $1: 2: 0.5$ & 27.5 & 15 & 150 & 2 & 73 \\
\hline \#21 ( \# 6) & $\beta$ & $1: 2: 1$ & 27.5 & 15 & 150 & 2 & 94 \\
\hline \# 22 & $\beta$ & $1: 2: 1.5$ & 27.5 & 15 & 150 & 2 & 100 \\
\hline$\# 23$ ( \# 22) & $\beta$ & $1: 2: 1.5$ & 27.5 & 15 & 150 & 2 & 100 \\
\hline \# 24 & $\gamma$ & $1: 2: 1$ & 27.5 & 15 & 150 & 2 & 76 \\
\hline
\end{tabular}

Table 2. Operating conditions of the experiments and inclusion yield obtained 


\section{References}

[1] J. Fages, H. Lochard, J.-J. Letourneau, M. Sauceau, E. Rodier, Particle generation for pharmaceutical applications using supercritical fluid technology, Powder Tech. 141 (2004) 219-226.

[2] J. Jung, M. Perrut, Particle design using supercritical fluids: literature and patent survey, J. Supercrit. Fluids 20 (2001) 179-219.

[3] H. Lochard, M. Sauceau, E. Rodier, J.-J. Letourneau, J. Fages, Use of RESS and SAS processes for powder generation of an active substance, in: Proc. $4^{\text {th }}$ World Congress on Particle Technology, Sydney, Australia, 2002, on CD-ROM.

[4] V. J. Stella, R. A. Rajewski, Cyclodextrins: their future in drug formulation and delivery, Pharm. Res. 14 (1997) 556-567.

[5] H. Qi, C. Sikorski, Controlled delivery using cyclodextrin technology, Pharm. Tech. Europe Nov. (2001) 17-27.

[6] T. Loftsson, M. Brewster, Pharmaceutical applications of cyclodextrins. 1. Drug solubilization and stabilization, J. Pharm. Sci. 85 (1996) 1017-1025.

[7] E. Fenyvesi, M. Vikmon, J. Szeman, E. Redenti, M. Delcanale, P. Ventura, J. Szejtli, Interaction of hydroxy acids with $\beta$-cyclodextrin, J. Incl. Phenom. Macrocycl. Chem. 33 (1999) 339-344.

[8] E. Redenti, L. Szente, J. Szejtli, Drug/cyclodextrin/hydroxy acid multicomponent systems. Properties and pharmaceutical applications, J. Pharm. Sci. 89 (2000) 1-8.

[9] P. Mura, F. Maestrelli, M. Cirri, Ternary systems of naproxen with hydroxypropyl$\beta$-cyclodextrin and aminoacids, Int. J. Pharm. 260 (2003) 293-302.

[10] G. Piel, B. Pirotte, I. Delneuville, P. Neven, G. Llabres, J. Delarge, L. Delattre, Study of the influence of both cyclodextrins and L-lysine on the aqueous solubility of nimesulide; Isolation and characterization of nimesulide-L-lysine-cyclodextrin complexes, J. Pharm. Sci. 86 (1997) 475-480. 
[11] R. Mammucari, N. R. Foster, Dense gas technology and cyclodextrins: State of the art and potential. Curr. Org. Chem. 12 (2008) 476-491.

[12] M. Kamihira, T. Asai, Y. Yamagata, M. Taniguchi, T. Kobayashi, Formation of inclusion complexes between cyclodextrins and aromatic compounds under pressurized carbon dioxide, J. Ferment. Bioeng. 69 (1990) 350-353.

[13] F. Giordano, M. Rillosi, G.P. Bettinetti, A. Gazzaniga, M. Majewski, M. Perrut, Interaction of supercritical fluids with drug/cyclodextrin inclusion compounds and physical mixtures, in: Proc. $8^{\text {th }}$ Int. Symposium on Cyclodextrins, 1996, pp. 193-196.

[14] T. Van Hees, G. Piel, B. Evrard, X. Otte, L. Thunus, L. Delattre, Application of supercritical carbon dioxide for the preparation of a piroxicam- $\beta$-cyclodextrin inclusion compound, Pharm. Res. 16 (1999) 1864-1870.

[15] T. Van Hees, V. Barillaro, G. Piel, P. Bertholet, S. Henry De Hassonville, B. Evrard, L. Delattre, Application of supercritical carbon dioxide for the preparation of drugcyclodextrin inclusion compounds, J. Incl. Phenom. Macrocycl. Chem. 44 (2002) 271-274.

[16] V. Barillaro, G. Piel, P. Bertholet, S. Henry de Hassonville. B. Evrard, L. Delattre, Inclusion of miconazole into cyclodextrins by means of supercritical carbon dioxide: influence of the addition of an acidic ternary compound, in: Proc. $6^{\text {th }}$ Int. Symposium on Supercritical Fluids, Versailles, France, 2003, pp. 1897-1902.

[17] V. Barillaro, P. Bertholet, S. Henry de Hassonville., E. Ziemons, B. Evrard, L. Delattre, G. Piel, Effect of acidic ternary compounds on the formation of miconazole/cyclodextrin inclusion complexes by means of supercritical carbon dioxide, J. Pharm. Sci. 7 (2004) 378-388.

[18] V. Barillaro, B. Evrard, L. Delattre, G. Piel., Oral bioavailability in pigs of a miconazole/hydroxypropyl-gamma-cyclodextrin/L-tartaric acid inclusion complex produced by supercritical carbon dioxide processing, AAPS J. 7 (2005) 149-155.

[19] V. Barillaro, G. Dive, P. Bertholet, B. Evrard, L. Delattre, M. Frederich, E. Ziémons, G. Piel, Theoretical and experimental investigations of organic acids/cyclodextrin 
complexes and their consequences upon the formation of miconazole/previous termcyclodextrin/acid ternary inclusion complexes, Int. J. Pharm. 342 (2007) 152-160

[20] V. Barillaro, G. Dive, P. Bertholet, B. Evrard, L. Delattre, E. Ziémons, G. Piel., Theoretical and experimental investigations on miconazole/cyclodextrin/acid complexes: Molecular modeling studies, Int. J. Pharm. 342 (2007) 152-160.

[21] E. Rodier, H. Lochard, M. Sauceau, J.-J. Letourneau, B. Freiss, J. Fages, A three step supercritical process to improve the dissolution rate of eflucimibe, Eur. J. Pharm. Sci. 26 (2005) 184-193.

[22] S. Papet, F. Marciacq, C. Joussot-Dubien, B. Freiss, M. Sauceau, H. Lochard, S. Sarrade, Supercritical $\mathrm{CO}_{2}$ antisolvent process for drugs precipitation: from lab-scale to cGMP compliant pilot-scale, in: Proc. $6^{\text {th }}$ Int. Symposium on Supercritical Fluids, Versailles, France, 2003, pp. 1689-1694.

[23] M. Charoenchaitrakool, F. Dehghani, N. Foster, Utilization of supercritical carbon dioxide for complex formation of ibuprofen and methyl- $\beta$-cyclodextrin, Int. J. Pharm. 239 (2002) 103-112.

[24] K. Hussein, M. Türk, M. A. Wahl, Preparation and evaluation of drug/ $\beta$ cyclodextrin solid inclusion complexes by supercritical fluid technology, in: Proc. $9^{\text {th }}$ Meeting on Supercritical Fluids, Trieste, Italy, 2004, on CD-ROM.

[25] Y. Tozuka, T. Fujito, K. Moribe, K. Yamamoto, Ibuprofen-cyclodextrin inclusion complex formation using supercritical carbon dioxide, J. Incl. Phenom. Macrocycl. Chem. 56 (2006) 33-37.

[26] M. Türk, G. Upper, M. Steurenthaler, K. Hussein, M. A. Wahl, Complex formation of Ibuprofen and $\beta$-Cyclodextrin by controlled particle deposition (CPD) using $\mathrm{SC}-\mathrm{CO}_{2}, \mathrm{~J}$. Supercrit. Fluids 39 (2007) 435-443.

[27] K. Hussein, M. Türk, M. A. Wahl, Comparative evaluation of ibuprofen/betacyclodextrin complexes obtained by supercritical carbon dioxide and other conventional methods, Pharm. Res. 24 (2007) 585-592. 
[28] K. Moribe, T. Fujito, Y. Tozuka, K. Yamamoto, Solubility-dependent complexation of active pharmaceutical ingredients with trimethyl-beta-cyclodextrin under supercritical fluid condition, J. Incl. Phenom. Macrocycl. Chem. 57 (2007) 289-295.

[29] K. Hussein, M. Türk, M. A. Wahl, Drug loading into $\beta$-cyclodextrin granules using a supercritical fluid process for improved drug dissolution, Eur. J. Pharm. Sci. 33 (2008) 306312

[30] S. Junco, T. Casimiro, N. Ribeiro, M. N. Da Ponte, H. C. Marques, Optimisation of supercritical carbon dioxide systems for complexation of naproxen: $\beta$-cyclodextrin, J. Incl. Phenom. Macrocycl. Chem. 44 (2002) 69-73.

[31] S. Junco, T. Casimiro, N. Ribeiro, M. N. Da Ponte, H. C. Marques, A comparative study of naproxen: $\beta$-cyclodextrin complexes prepared by conventional methods and using supercritical carbon dioxide, J. Incl. Phenom. Macrocycl. Chem. 44 (2002) 117-121.

[32] R. Mammucari, F. Dehghani, N. Foster, Dense gas processing of micron-sized drug formulations incorporating hydroxypropylated and methylated beta-cyclodextrin, Pharm. Res. 23 (2006) 429-437.

[33] B. Marongiu, A. Piras, S. Porcedda, G. Delogu, D. Fabbri, M.A. Dettori, Cyclodextrin inclusion compounds by supercritical carbon dioxide, in: Proc. $8^{\text {th }}$ Meeting on Supercritical Fluids, Bordeaux, France, 2002, pp. 327-332.

[34] S. Lai, E. Locci, A. Piras, S. Porcedda, A. Lai, B. Marongiu, Imazalilcyclomaltoheptaose ( $\beta$-cyclodextrin) inclusion complex: preparation by supercritical carbon dioxide and ${ }^{13} \mathrm{C}$ CPMAS and ${ }^{1} \mathrm{H}$ NMR characterization, Carbohydr. Res. 338 (2003) 22272232.

[35] S. Junco, T. Casimiro, H. C. Marques, Inclusion complex formation of salicylic acid in $\beta$ - and acetylated- $\beta$-cyclodextrins in supercritical carbon dioxide, in: Proc. $9^{\text {th }}$ Meeting on Supercritical Fluids, Trieste, Italy, 2004, on CD-ROM.

[36] M. Wu, Y. Yuguchi, T. Kumagai, T. Endo, T. Hirotsu, Nano-complex formation of cyclodextrin and azobenzene using supercritical carbon dioxide, Chem. Commun. 11 (2004) 1288-1289. 
[37] T. Toropainen, T. Heikkila, J. Leppanen, L. Matilainen, S. Velaga, P. Jarho, J. Carlfors, V. P. Lehto, T. Jarvinen, K. Jarvinen, Crystal structure changes of gammacyclodextrin after the SEDS process in supercritical carbon dioxide affect the dissolution rate of complexed budesonide, Pharm. Res. 24 (2007) 1058-1066.

[38] T. Toropainen, L. Matilainen, S. Velaga, T. Heikkila, P. Jarho, J. Carlfors, V. P. Lehto, T. Jarvinen, K. Jarvinen, Preparation of solid budesonide $/ \gamma$-cyclodextrin complexes with a novel single-step supercritical fluid process (SEDS), Eur. J. Pharm. Sci. 28 (2006) S17S17.

[39] T. Toropainen, S. Velaga, T. Heikkila, L. Matilainen, P. Jarho, J. Carlfors, V. P. Lehto, T. Jarvinen, K. Jarvinen, Preparation of budesonide/gamma-cyclodextrin complexes in supercritical fluids with a novel SEDS method, J. Pharm. Sci. 95 (2006) 2235-2245.

[40] N. Bandi, W. Wei, C. B. Roberts, L. P. Kotra, U. B. Kompella, Preparation of budesonide- and indomethacin-hydroxypropyl- $\beta$-cyclodextrin (HPBCD) complexes using a single-step, organic-solvent-free supercritical fluid process, Eur. J. Pharm. Sci. 23 (2004) 159168.

[41] B. Wang, J. He, D. Sun, R. Zhang, B. Han, Y. Huang, G. Yang, Preparation of $\beta$ cyclodextrin-polyaniline complex in supercritical $\mathrm{CO}_{2}$, Eur. Polym. J. 41 (2005) 2483-2487.

[42] T. H. Jung, H. S. Park, H. S. Kwak, Optimization of cholesterol removal by crosslinked beta-cyclodextrin in egg yolk, Food Sci. Biotechnol. 14 (2005) 793-797.

[43] G. Filardo, M. Di Blasi, A. Galia, A. Ponchel, H. Bricout, A.D. Sayede, E. Monflier, Peracetylated $\beta$-cyclodextrin as solubilizer of arylphosphines in supercritical carbon dioxide, J. Supercrit. Fluids 36 (2006) 173-181.

[44] A. H. Al-Marzouqi, I. Shehatta, B. Jobe, A. Dowaidar, Phase solubility and inclusion complex of itraconazole with beta-cyclodextrin using supercritical carbon dioxide, J. Pharm. Sci. 95 (2006) 292-304.

[45] H. A. Hassan, A. H. Al-Marzouqi, B. Jobe, A. A. Hamza, G. A. Ramadan, Enhancement of dissolution amount and in vivo bioavailability of itraconazole by 
complexation with $\beta$-cyclodextrin using supercritical carbon dioxide, J. Pharm. Biomed. Anal. 45(2007), 243-250

[46] S.-Y. Lee, I.-I. Jung, J.-K. Kim, G.-B. Lim, J.-H. Ryu, Preparation of itraconazole/HP- $\beta$-CD inclusion complexes using supercritical aerosol solvent extraction system and their dissolution characteristics, J. Supercrit. Fluids, 44 (2008), 400-408

[47] H. S. Hwang, M. Y. Lee, Y. T. Jeong, S.-S. Hong, Y.-S. Gal, K. T. Lim, Complex formation of semifluorinated $y$-cyclodextrin and surfactants in liquid carbon dioxide, Ind. Eng. Chem. Res. 45 (2006) 3434-3437.

[48] B. Wang, J. He, D. H. Sun, R. Zhang, B. X. Han, Utilization of supercritical carbon dioxide for the preparation of 3-hydroxyflavone and beta-cyclodextrin complex, J. Incl. Phenom. Macrocycl. Chem. 55 (2006) 37-40.

[49] A. H. Al-Marzouqi, B. Jobe, A. Dowaidar, F. Maestrelli, P. Mura, Evaluation of supercritical fluid technology as preparative technique of benzocaine-cyclodextrin complexes-Comparison with conventional methods, J. Pharm. Biomed. Anal. 43 (2007) $566-574$.

[50] A. H. Al-Marzouqi, B. Jobe, G. Corti, M. Cirri, P. Mura, Physicochemical characterization of drug-cyclodextrin complexes prepared by supercritical carbon dioxide and by conventional techniques, J. Incl. Phenom. Macrocycl. Chem. 57 (2007) 223-231.

[51] S. W. Jun, M.-S. Kim, J.-S. Kim, H. J. Park, S. Lee, J.-S. Woo, S.-J. Hwang, Preparation and characterization of simvastatin/hydroxypropyl- $\beta$-cyclodextrin inclusion complex using supercritical antisolvent (SAS) process, Eur. J. Pharm. Biopharm. 66 (2007) 413-421.

[52] A. Galia, E. C. Navarre, O. Scialdone, M. Ferreira, G. Filardo, S. Tilloy, E. Monflier, Complexation of phosphine ligands with peracetylated beta-cyclodextrin in supercritical carbon dioxide: Spectroscopic determination of equilibrium constants, J. Phys. Chem. B 111 (2007) 2573-2578.

[53] G. P. Blanch, M. L. Ruiz del Castillo, M. del Mar Cajaa, M. Pérez-Méndez, S. Sánchez-Cortés, Stabilization of all-trans-lycopene from tomato by encapsulation using cyclodextrins, Food Chemistry 105 (2007) 1335-1341. 
[54] A. Bouchard, N. Jovanovic, G. W. Hofland, W. Jiskoot, E. Mendes, D. J. A. Crommelin, G.-J. Witkamp, Supercritical fluid drying of carbohydrates: Selection of suitable excipients and process conditions, Eur. J. Pharm. Biopharm. 68 (2008), 781-794

[55] N. Jovanovic, A. Bouchard, G. W. Hofland, G.-J. Witkamp, D. J. A. Crommelin, W. Jiskoot, Stabilization of IgG by supercritical fluid drying: Optimization of formulation and process parameters, Eur. J. Pharm. Biopharm. 68 (2008), 183-190

[56] A. Bounaceur, E. Rodier, J. Fages, Study of the maturation of a ketoprofen/ $\beta$ cyclodextrin mixture, assisted by supercritical fluid, J. Supercrit. Fluids 41 (2007) 429-439.

[57] A. H. Al-Marzouqi, A. Solieman, I. Shehadi, A. Adem, Influence of the preparation method on the physicochemical properties of econazole-beta-cyclodextrin complexes, J. Incl. Phenom. Macrocycl. Chem 60 (2008), 85-93

[58] R.N. Brogden, R.C. Heel, T.M. Speight, G.S. Avery, Piroxicam: a review of its pharmacological properties and therapeutic efficacy, Drugs 22 (1981) 165-187.

[59] X. Deroubaix, A. Stockis, A.M. Allemon, E. Lebacq, D. Acerbi, P. Ventura, Oral bioavailability of CHF1194, an inclusion complex of piroxicam and $\beta$-cyclodextrin, in healthy subjects under single dose and steady-state conditions, Eur. J. Clin. Pharmacol. 47 (1995) $531-536$

[60] B.G. Woodcock, D. Acerbi, P.G. Merz, S. Rietbrock, N. Rietbrock, Supermolecular inclusion of piroxicam with $\beta$-cyclodextrin: pharmacokinetic properties in man, Eur. J. Rheumatol. Inflamm. 12 (1993) 12-28.

[61] D. Acerbi, G. Bovis, F. Carli, M. Pasini, L. Pavesi, T. Peveri, Biopharmaceutical optimisation of $\beta$-cyclodextrin inclusion compounds, Drug Invest. 2 (1990) 29-36.

[62] E. Redenti, T. Peveri, M. Zanol, P. Ventura, G. Gnappi, A. Montenero, A Study on the differentiation between amorphous piroxicam: $\beta$-cyclodextrin complex and a mixture of the two amorphous components, Int. J. Pharm. 129 (1996) 289-294.

[63] T. Van Hees, G. Piel, S. Henry De Hassonville, B. Evrard, L. Delattre, Determination of the free/included piroxicam ratio in cyclodextrin complexes: comparison 
between UV spectrophotometry and differential scanning calorimetry, Eur. J. Pharm. Sci. 15 (2002) 347-353.

[64] S. J. Macnaughton, I. Kikic, N. Foster, P. Alessi, A. Cortesi, I. Colombo, Solubility of anti-inflammatory drugs in supercritical carbon dioxide, J. Chem. Eng. Data 41 (1996) 1083-1086.

[65] C. R. Wilke, P. Chang, Correlation of diffusion coefficient in dilute solutions, AIChE J. (1955) 1:264. 


\section{Legend to Figures}

Figure 1. Formula of $\beta$-cyclodextrin

Figure 2. Formula of piroxicam

Figure 3. Typical DSC curves: physical mixture (solid line) and SCF processed sample (dashed line)

Figure 4. Inclusion yield $T_{C X}^{P I}$ vs. LL molar ratio for different water contents

Figure 5. SEM pictures of raw materials: PI (a) and CD (b)

Figure 6. SEM pictures of partially (a) and completely (b) complexed powders

Figure 7. Dissolution rate profiles for unprocessed PI and its physical mixtures

Figure 8. Dissolution rate profiles for different SCF processed samples 


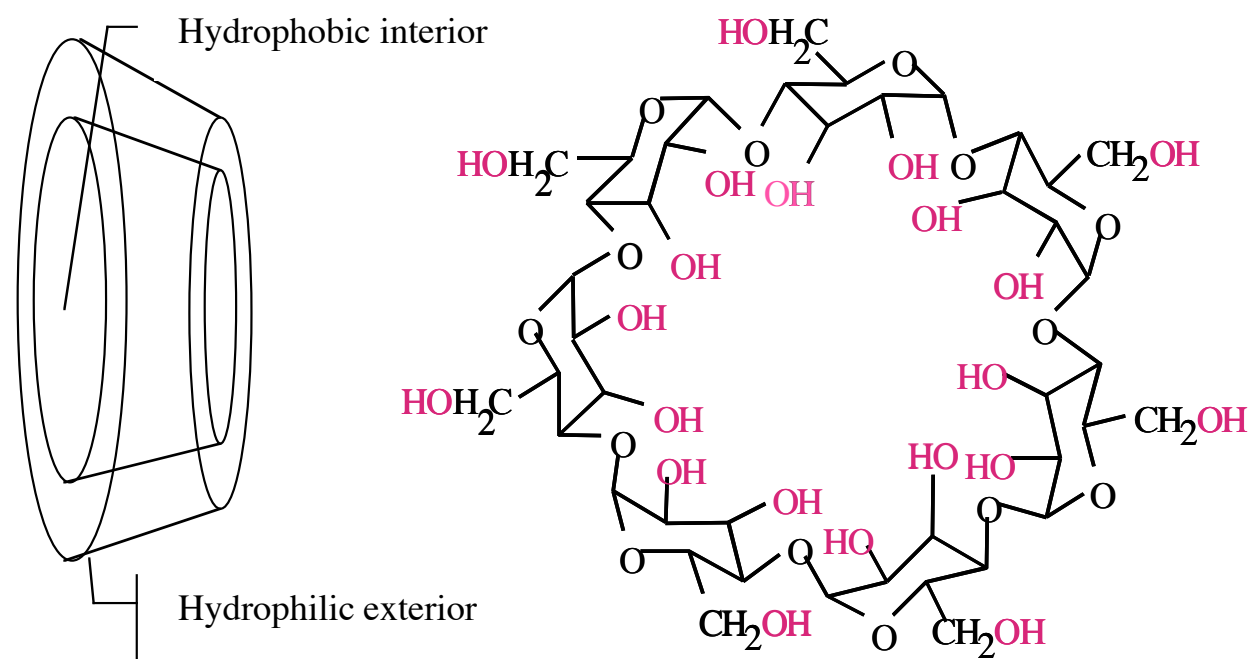

Figure 1

M. Sauceau, E. Rodier, J. Fages

Preparation of Inclusion Complex of Piroxicam with cyclodextrin by Using

Supercritical Carbon Dioxide 


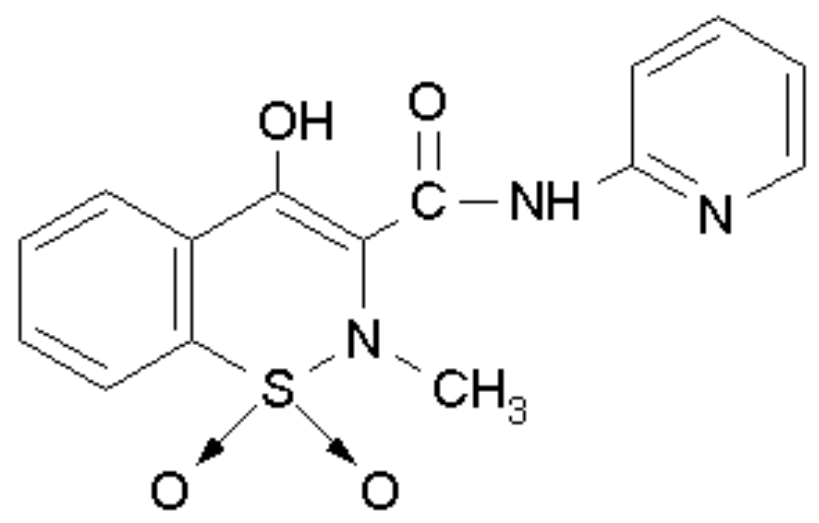

Figure 2

M. Sauceau, E. Rodier, J. Fages

Preparation of Inclusion Complex of Piroxicam with cyclodextrins by Using Supercritical Carbon Dioxide 


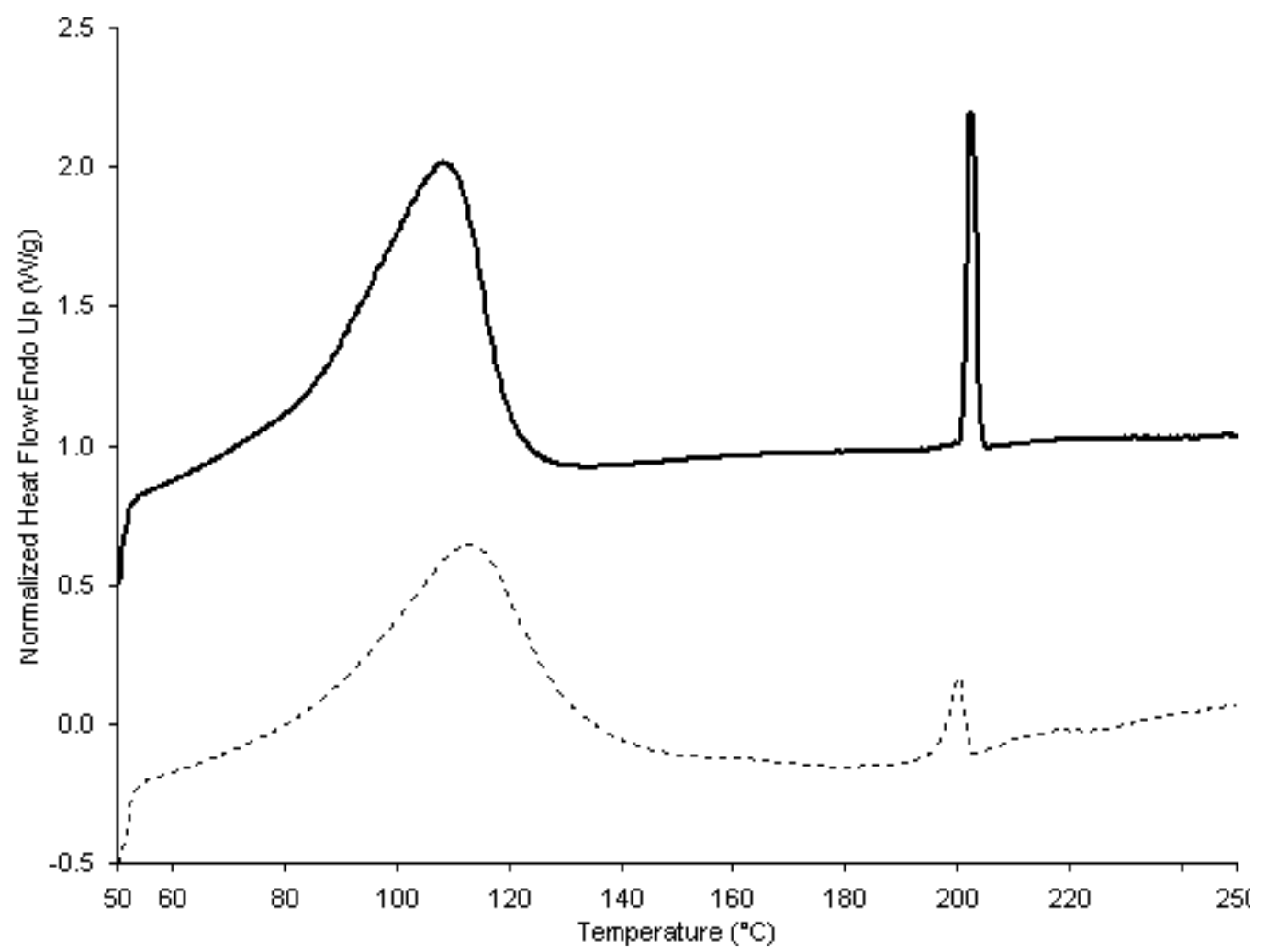

Figure 3

M. Sauceau, E. Rodier, J. Fages

Preparation of Inclusion Complex of Piroxicam with cyclodextrin by Using Supercritical Carbon Dioxide 


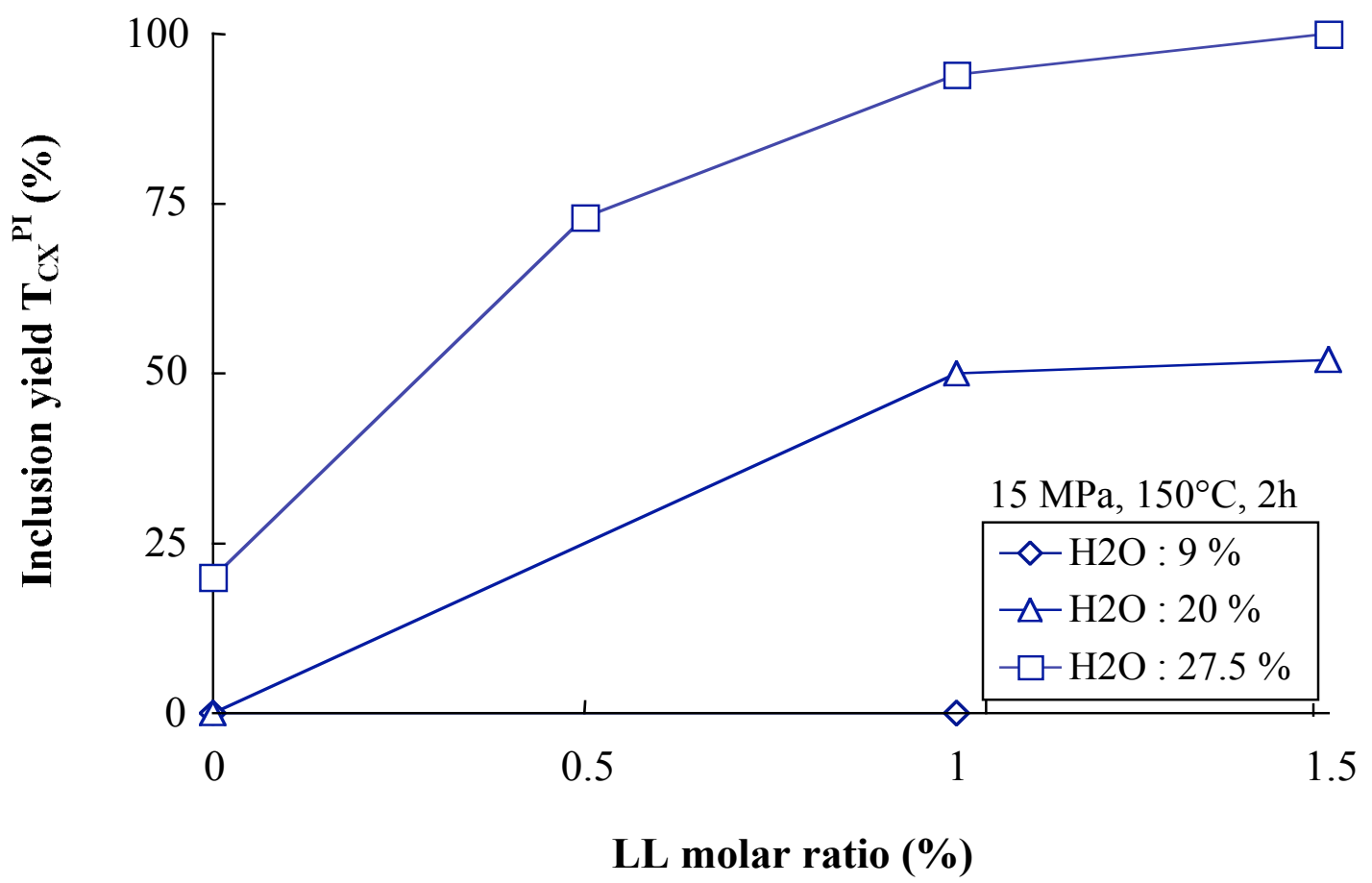

Figure 4

M. Sauceau, E. Rodier, J. Fages

Preparation of Inclusion Complex of Piroxicam with cyclodextrin by Using

Supercritical Carbon Dioxide 

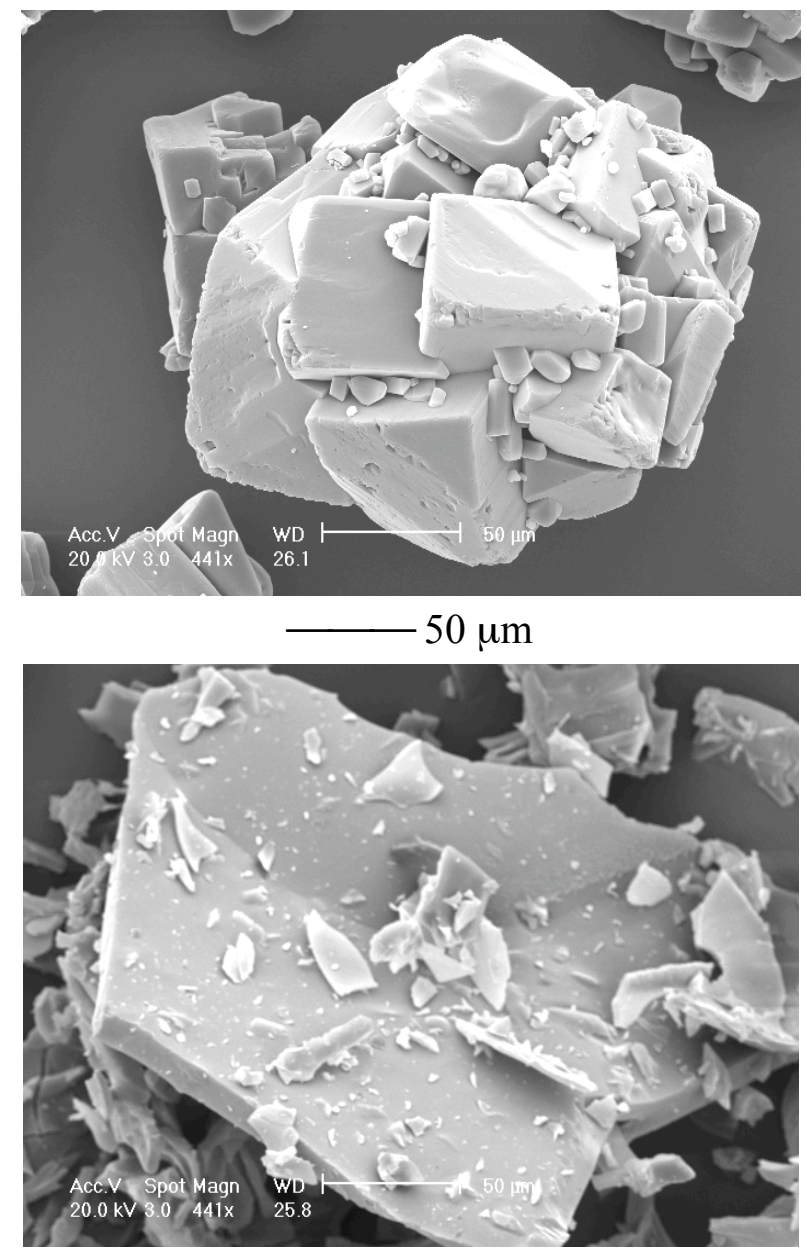

(a)

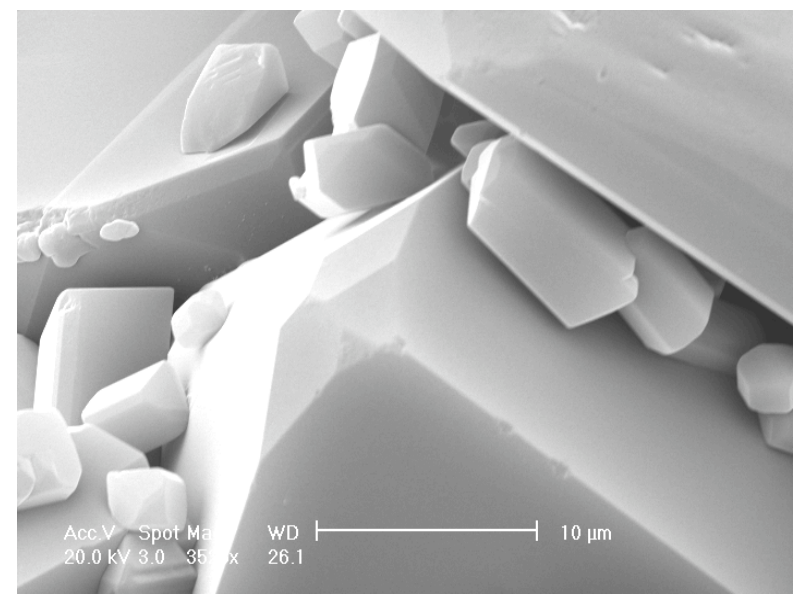

$10 \mu \mathrm{m}$

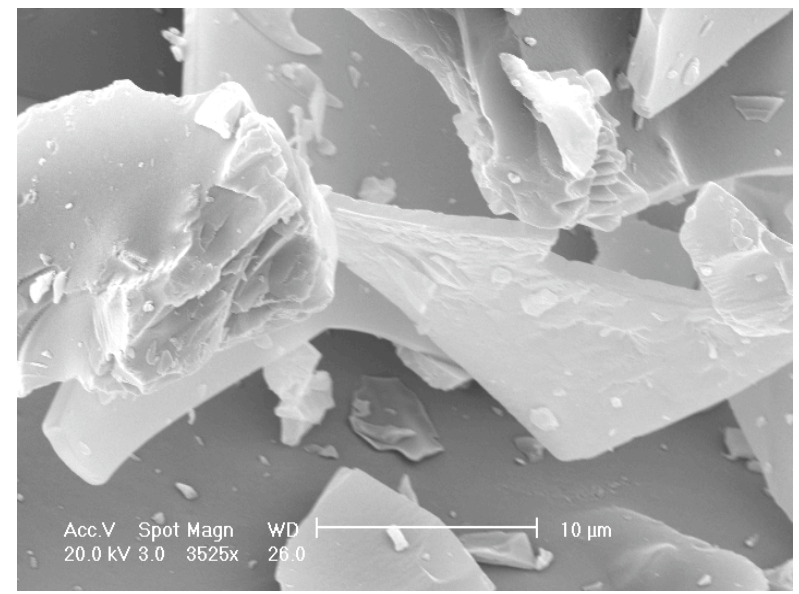

\section{Figure 5}

M. Sauceau, E. Rodier, J. Fages

Preparation of Inclusion Complex of Piroxicam with cyclodextrin by Using Supercritical

Carbon Dioxide 


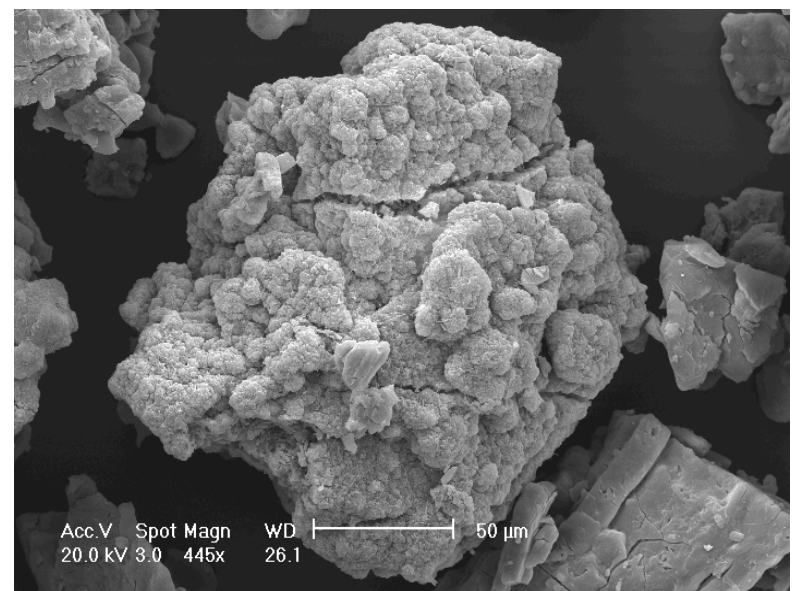

$50 \mu \mathrm{m}$

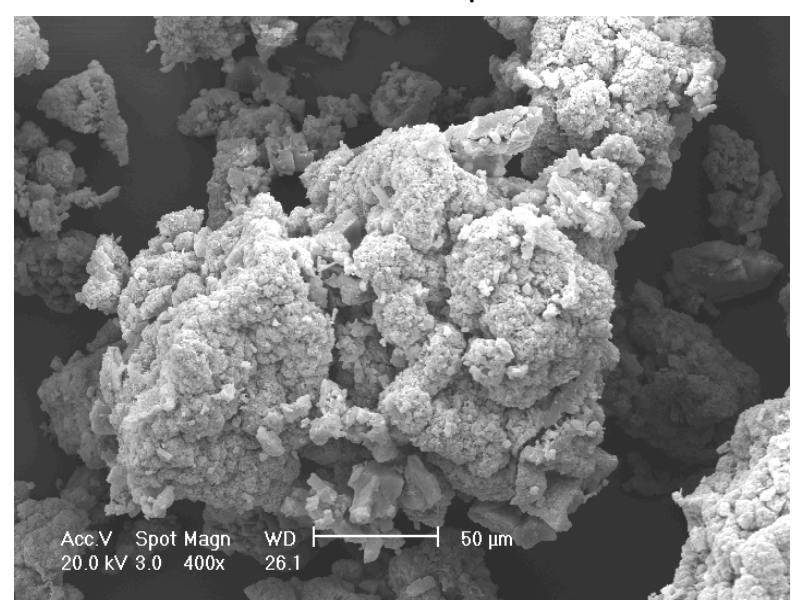

(a)

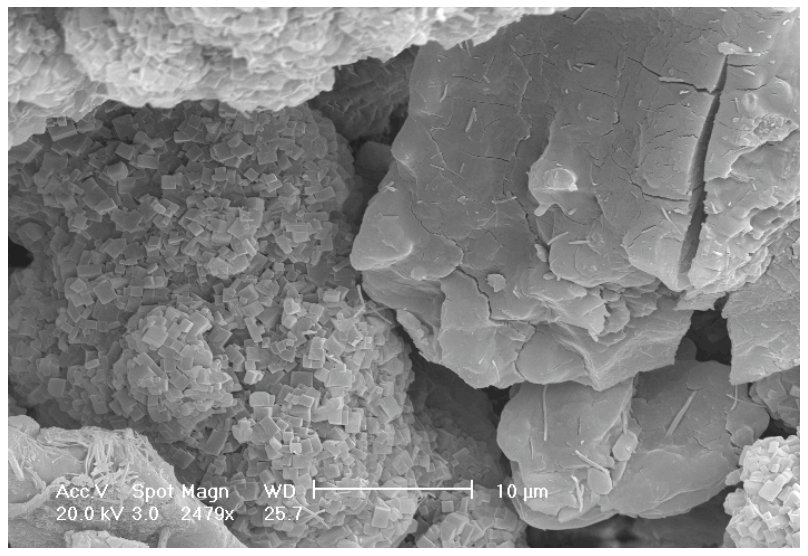

$10 \mu \mathrm{m}$

(b)

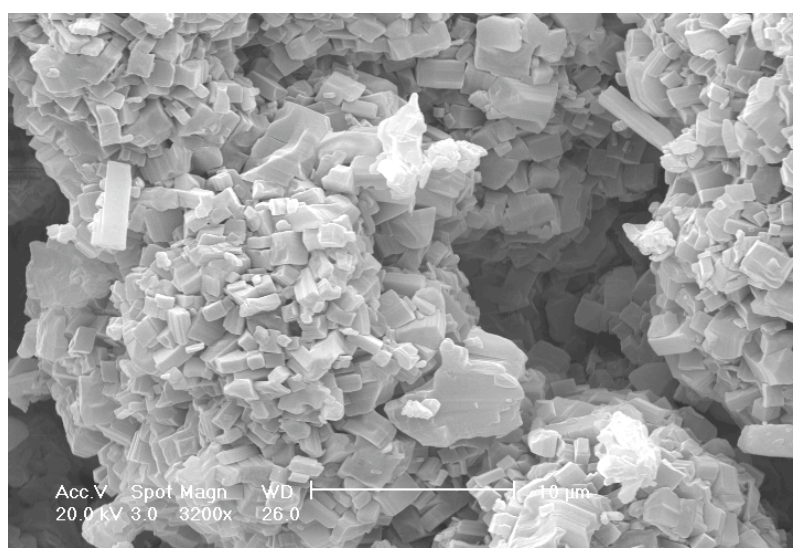

Figure 6

M. Sauceau, E. Rodier, J. Fages

Preparation of Inclusion Complex of Piroxicam with cyclodextrin by Using Supercritical Carbon Dioxide 


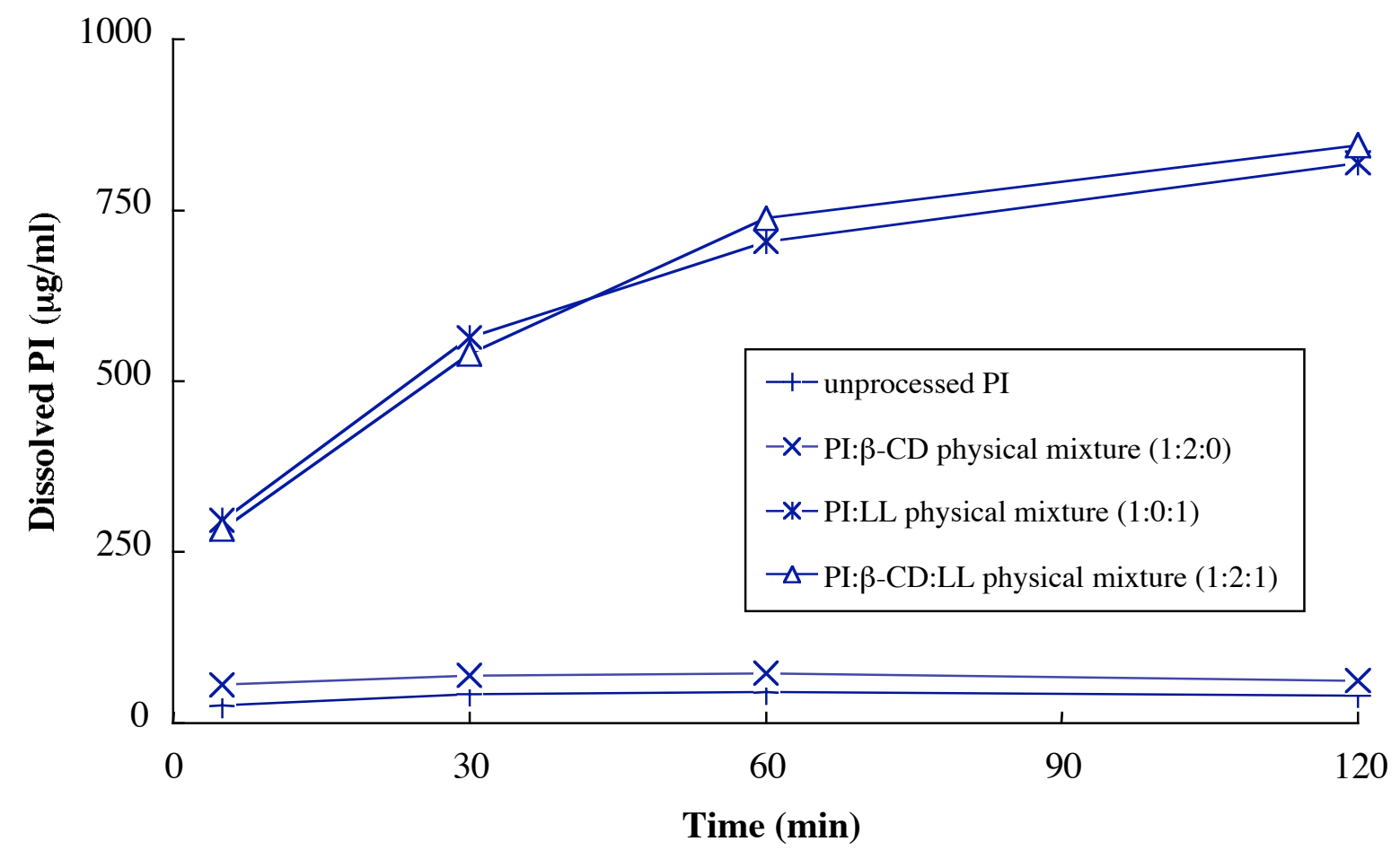

Figure 7

M. Sauceau, E. Rodier, J. Fages

Preparation of Inclusion Complex of Piroxicam with cyclodextrin by Using Supercritical Carbon Dioxide 


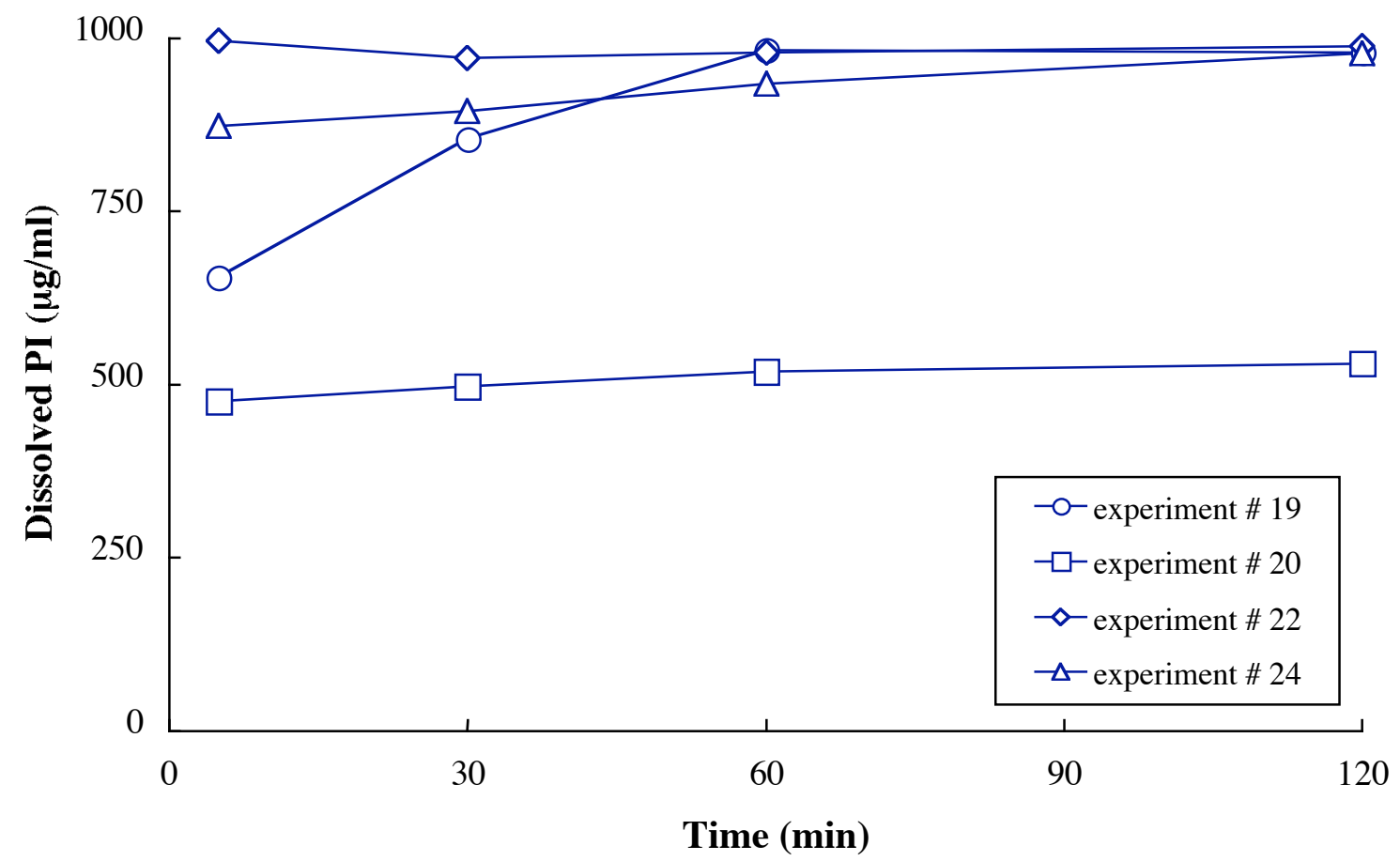

Figure 8

M. Sauceau, E. Rodier, J. Fages

Preparation of Inclusion Complex of Piroxicam with cyclodextrin by Using

Supercritical Carbon Dioxide 